\title{
An assessment of alignment between development interventions and monitoring and evaluation in Limpopo Province, South Africa
}

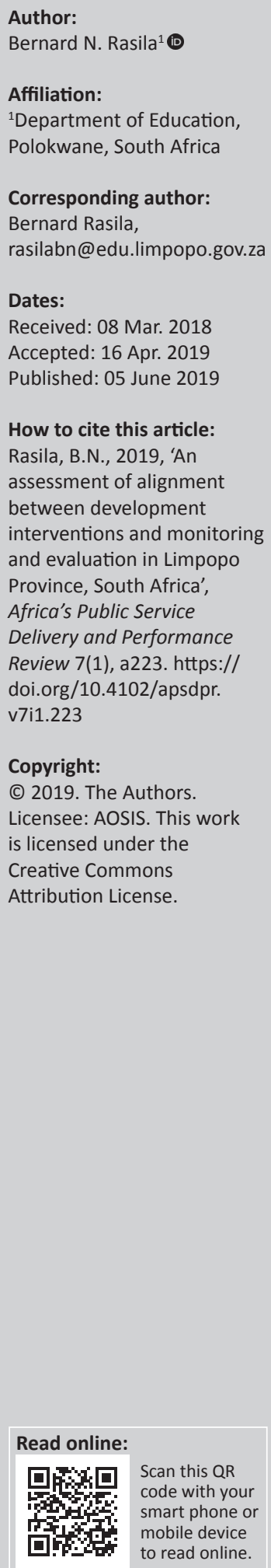

Background: The Limpopo Provincial Government, like other provinces of South Africa, has developed the Limpopo Development Plan (LDP) 2015/2019. This has been a revision of the previous developed plans that also had to be revised without the realisation of their goals. It has come to be the norm in government to develop plans that fail to be implemented. This is attributed to a lack of effective monitoring and evaluation (M\&E) systems in departments. Most of the departments in Limpopo have under-capacitated and under-staffed M\&E directorates; hence, they fail to align development interventions as in the LDP and M\&E processes.

Aim: The aim of this study was to probe the alignment between intervention plans and M\&E. When there is a lack of alignment, there is an obvious lack of monitoring if government activities are geared to strengthen the realisation of the development plan, failure of which leads to a waste of resources and continuous under-development in the province. Failing to realise that the set goals results in government are being postponed by the continual drafting and redrafting of the same goals in different tones and sentences.

Setting: The M\&E should be at the centre of decision-making as it gives evidence-based decisions. This is important in the Limpopo Province which is one of the poorest provinces in the country.

Method: This study adopted the techniques of qualitative methodology where assessment is conducted to find out the alignment between the development interventions as set out in the LDP and the concept of result-based management which is key in M\&E. The Annual Performance Plans that are not directly responding to the goals of the National Development Plan 2030 and the LDP 2015/2019 in particular.

Results: This study demonstrates that the lack of alignment between the LDP and M\&E processes leads to failure in realising the goals of the LDP on the one hand, and the ability to improve the living conditions of its citizenry on the other hand.

Conclusion: It can be concluded that without effective M\&E systems government will continue to waste resources without getting improvement. All that is done by the government should be aligned to proper M\&E systems.

Keywords: National development plan; Limpopo development plan; monitoring and evaluation; development interventions; decision-making; result-based management.

\section{Introduction}

Governments across the world have development interventions or plans. These interventions are meant to uplift the living condition of citizens. They also have timeframes that can be of short or long term. The development interventions are plans that reflect the agenda of the Medium Term Strategic Framework (MTSF). These plans are drawn from the manifestos of the ruling party. Policies developed are intended to ensure that the commitments entailed in the manifesto are strategically achieved.

In May 2010, South Africa's President Mr Jacob Zuma appointed a planning commission that developed the National Development Plan (NDP) tagged vision 2030. The NDP 2030 was developed to guide government institutions towards making sure that living conditions are improved. In addition, the NDP 2030 seeks to mobilise all South Africans to be actively engaged in personal and organisational development, expansion of the economy and building a capable and developmental state by 2030 .

Different from the then economic policy, the Growth, Employment and Redistribution (GEAR), introduced by the then president of South Africa, Mr Thabo Mbeki, the NDP 2030 is a long-term 
plan aimed at improving not only economic sectors but also other areas, such as the socio-economic realities experienced in the country. The NDP focuses on comprehensive improvement of living condition of all the people, ranging from feeling safe to having dignity restored to all, irrespective of how active they are in economic matters. On the contrary, the Accelerated and Shared Growth Initiative for South Africa (ASGISA) also focuses on accelerating and growth with more emphasis on economic activities. The two policies were more operational at the national sphere of government, while with the NDP provinces were compelled to craft their own development plans that feed on the realisation of the goals of NDP 2030. These plans also talk about what needs to happen at the local or municipality sphere, including ensuring that people become active participants in matters of governance. The Limpopo Development Plan (LDP) developed in 2009 comes to an end or expires at the end of 2019. What is regarded as normal is that when the period lapses, the government brings different stakeholders to look at what has been achieved and craft new intervention plans as the main content of their new development plan. The main change becomes visible in the years that are constantly postponed.

Interesting questions are often asked: will the NDP ever be fully implemented and if indeed by 2030, will many, if not all of its objectives, be realised? Many people interviewed believe that there are elements of the NDP that are being well implemented but believe also that at the end of 2030, government may go back to the drawing board with many goals not achieved. However, it needs to be noted that the NDP 2030 supports many initiatives targeted by the ASGISA and GEAR as the two were mainly meant to improve economic status and hence bring in development in the country. The constitutional mandate of government always leads in channelling programmes of government towards improvement of living conditions as the Bill of Rights of the Constitution of South Africa (Act 108 of 1996) has to be uphold by government and all other institutions, as well as people themselves.

Citing Baradei, Abdelhamid and Wally (2014), Wotela (2017a) indicates that the reason for absent or ineffective monitoring and evaluation (M\&E) of development plans in some African countries was lack of political will. This has impacted the shape and focus of the departmental Annual Performance Plans (APPs) as the technocrats strive by all ways to make political leaders happy in return for job benefits. One reason for the lack of political will is that most findings of the M\&E may not be politically desirable as politicians become obsessed with protecting their positions and not pure service to the people. On the contrary, an organisation that is carrying out any project needs to have some systems in place to ensure that its work is going according to the plan (Bakewell, Adams \& Prat 2013). This process will also allow room for methodological interventions.

The establishment of Department of Planning, Monitoring and Evaluation saw departments and provinces embarking on building M\&E capacities (Policy on Monitoring and Evaluation for Limpopo Department of Education, June 2011).
This study focuses on the development intervention as set out in the LDP 2015/2019 and the role or importance of M\&E in the realisation of the goals of set interventions.

The main aim of this article is to highlight the importance of effective M\&E systems in ensuring that all developmental goals of governments are realised. The article is also aimed at indicating gaps that should be envisaged if there is a lack of effective M\&E that has been a challenge in government service delivery, which affects mainly 'poor' provinces such as Limpopo. Once there is effective M\&E, this will lead to improved service delivery, and shifting the goalposts will not be an easy option for government officials when they fail to realise set interventions. State funds will also be saved if there are effective $M \& E$ processes, as little or no money will go to waste and there will be little or no funds flooding to corrupt activities.

The study adopted techniques of qualitative methodology. Most of the data were taken first from desktop and assessment processes of the APPs and other documents with the aim of focussing on their alignment towards enhancing the realisation of the goals of the LDP. Self-administered questionnaires were distributed to, among others, members of M\&E in different departments of Limpopo Provincial Government and people involved in planning divisions of their departments, as well as ordinary beneficiaries of government basic services.

The results indicated that indeed there was a lack of effective M\&E processes in government in general and Limpopo Provincial Government in particular, and this leads to failure to realise the overall goals of LDP. This study also indicates many challenges, including poor consideration of the goals of the development plan when different departments do their APPs. The fact that M\&E directorates are mostly under-staffed at times with incompetent officials also contributes to the poor alignment in the development goals and daily performance. There are ways to improve on $M \& E$ recommended in this article.

\section{Literature review}

\section{Development interventions in Limpopo Province}

This section seeks to define and discuss development interventions in Limpopo Province. This will be more comprehensive if the two components (development and interventions) are also simplified.

According to the LDP of 2015/2019, development is defined as broad-based improvements in the standard and quality of living conditions of people in a country, province or municipality, including small villages. For development to happen, there is a need for involvement of all stakeholders. These stakeholders include government, business, non-profitmaking organisations (NPOs) and the citizens themselves. Citizen participation in matters of their development is emphasised more on local sphere of government in South Africa as per the White Paper on Local Government 
of 1998. However, the understanding or perceptions levelled against the Reconstruction and Development Programme (RDP) introduced to unbalance the imbalances, created by apartheid government, in a new democratic South Africa seem to continue to create dependency nation, which simply just seat, wait for government to deliver, protest if not receiving what they need at their time, destroy and government comes and fix the damage (Rasila \& Mudau 2013a). For you get a person living in a government-sponsored house, receiving indigent services yet going out to destroy a library because a tarred road is needed for example or they simply hate a local councillor.

On the contrary, interventions are plans made or established to contribute in bringing change from one stage to the next stage. In Limpopo Province, government has developed the LDP $2015 / 2019$ as part of intervening to reduce under-development and improve living conditions of its citizens. The main focus of the plan is to bring development through intensification of economic transformation, social transformation and improvement of service delivery.

Limpopo is one of the nine provinces in South Africa. It comprises five district municipalities: Capricorn, Greater Sekhukhune, Mopani, Vhembe and Waterberg (LDP 2015/2019). All districts are rural in nature as they comprise many rural communities with limited urban or semi-urban areas. This suggests that there are many rural areas characterised by few economic opportunities. Limpopo Province shares international borders with three countries: Botswana, Zimbabwe and Mozambique.

As argued by Masiapato and Wotela (2017), rural areas in South Africa were exposed to poor service delivery processes by the apartheid government, and Limpopo rural areas were not free from the discrimination system caused by the apartheid regime where areas occupied by white people were provided with more resources than those allocated to black people. This left the African-dominated areas underdeveloped. The White Paper on Local Government (1999) seeks participatory democracy, which leads to getting all citizens to participate in their development initiatives at equal levels. Unfortunately, even today, Limpopo Province is impeded by a large number of young, educated and skilled people migrating to other provinces for jobs and improved living conditions. They then leave implementation gaps in the available economic activities, leaving behind more of economic disadvantaged generations.

Considering that the unemployment challenge stands at $21.6 \%$ in Limpopo according the quarterly labour force survey of 2017, indeed the province needs interventions that include improving mining and, agro-processing as emphasised during the recent Provincial Economic Seminar (Mabanga 2016). Following are the 14 outcomes of the LDP 2015/2019 set as development interventions of the province:

- Outcome 1: Quality basic education

- Outcome 2: Long and healthy life
- Outcome 3: Safety to all people

- Outcome 4: Decent employment through inclusive growth

- Outcome 5: Skilled and capable workforce

- Outcome 6: Competitive economic infrastructure

- Outcome 7: Comprehensive rural development

- Outcome 8: Human settlement development

- Outcome 9: Developmental local government

- Outcome 10: Environmental protection

- Outcome 11: Regional integration

- Outcome 12: Developmental public service

- Outcome 13: Inclusive social protection system

- Outcome 14: Social cohesion

The LDP 2015/2019 is therefore the main development intervention guideline for Limpopo Province in 2015-2019.

Through the Department of Cooperative Governance, Housing and Traditional Affairs (COGHTA), for example, the province provides houses to qualifying citizens. This is one intervention that brings to previously disadvantaged people dignity in line with Outcome 8 . Complaints frequently received from the beneficiaries are about poor quality and incomplete housing projects. This implies that the main challenge is an ineffective M\&E function in the implementation of housing projects as the challenge is recurring year after the other.

On the contrary, during 2005 grade 12 results' announcement at the beginning of the 2016 academic year and in subsequent years, Provincial Member of the Executive Council (MEC) for Education announces names of schools referred to as 'Serial poor performers' for performing poorly for five or more years in succession. It can be argued that these schools cannot contribute to the realisation of the Outcome 1 of the LDP 2015/2019, that of improving quality of basic education. Only individual learners may improve, while the majority are remaining behind and continue to struggle at the higher academic levels.

The Limpopo Department of Education has developed an Education Improvement Strategy that, among others, demands principals of the schools draft and report on initiatives they embark on for improvement. This needs to be monitored by curriculum advisors, circuit managers and the provincial education office. Continuous poor performance can be one element to prove that there is poor M\&E. The department also seems to have no alternative plans beyond just developing the strategies that are less monitored. There is, therefore, a need for the departmental M\&E, newly developed directorate, which is less than 3 years old, to strengthen relationships with all other directorates and branches and work together with the aim of improving departmental service delivery. Because education is a societal matter, other sectors also need to be strengthened to ensure that they contribute in provisioning of M\&E services to the education sector. 


\section{The concept of monitoring and evaluation in scrutiny}

The monitoring and evaluation defined in the context of development

Bakewell et al. (2003) view M\&E as a process that tracks continuous progress and periodically assesses progress for the sake of accountability, transparency and improved management services.

Bakewell et al. (2003) proceed to separate the process of monitoring from the process of evaluation where they indicate that monitoring is done continuously, focussing mostly on the fact that the project is progressing as planned and enables adjustment in a methodical way. They further indicate that evaluation is mostly focussing on assessing periodically the relevance, efficiency and impact of the project or intervention.

In the context of development, it can be argued that it is only when $M \& E$ is effective that planned projects get completed and stay relevant and therefore will contribute to development.

\section{Importance of monitoring and evaluation in} implementation of development interventions in Limpopo

According to Statistics South Africa (STATSSA) 2011 Census, there are more than 5.4 million people in Limpopo Province. However, the Limpopo Community Survey conducted by STATSSA in 2016 indicates that the population has increased to 5.8 million. This could be more, considering there are some flocking to the country undocumented.

Statistics South Africa continues to indicate that the Limpopo Province is the fifth largest province in the country. It comes after Gauteng, KwaZulu-Natal, Eastern Cape and Western Cape. In terms of access to basic services, the province has highest proportion of 'Owned and fully paid-off' homes in the country with $65.4 \%$. Approximately $7.5 \%$ of households in the province own their main dwelling.

There are also developmental challenges that need intervention. These include the increase in the shortage of, or decrease in access to piped water, which was at $80 \%$ in 2016. Electricity access increased from 39.2\% in 2011 to $93 \%$ in 2016 . Generally, the survey indicates that poverty headcount in Limpopo has increased from 10.1\% in 2011 to $11.5 \%$ in 2016.

There are other challenges to development that need intervention, including poor road infrastructure and general poor living conditions; hence, there is the need for effective M\&E processes in programmes, including the increment of capability and skills to be able to join economic activities.

In the Provincial Economic Seminar under the theme 'An Industrialisation Path towards Creating Sustainable Jobs and Reducing Poverty for Limpopo Province', the province committed to embark on effective planning so that it can attract investors (Mabanga 2016). The Premier of the Province,
Mr Stan Mathabatha, committed to improve in matters of rural development through the promotion of activities in mining, infrastructure, Internet Communication Technology (ICT), agri-process and the knowledge economy.

Just like the many announcements made during political speeches such as the State of Province Address 2016, 2017, 2018-2019 and despite many types of attempted service delivery, the summit may end up not yielding positive results because of the lack of M\&E systems. A question may be asked as follows: Why is M\&E important?

As put by Bakewell et al. (2003), M\&E provides for accountability. This is because those implementing the project do so on behalf of others and they have to account and apply their minds fully in executing their tasks and do so as planned. All that government does is to provide improved living condition to its citizenry.

Wotela (2017a) supports the accountability role of M\&E, but adds that this process, to some extent, provides transparency and good governance. However, the process of M\&E should be linked to the development intervention and public policy (Wotela 2017a). On the contrary, Adejuwon (2014) strongly emphasised that there is a need to strengthen debates about the role, scope and performance of organisations and public sector. In addition, Rasila and Mudau (2013a) have a view that it is only if the community members get involved in matters of their development that they can enforce accountability.

When there is accountability in implementing projects for development, there will be improvement - improvement in how people do things and getting proper performance and proper products. This is only realised when there is effective M\&E.

Bakewell et al. (2003) added that the M\&E process improves performance. Once a mistake is deduced during M\&E process of a project, there is always room for methodological interventions instead of the mistake deduced when project is at the end. On the contrary, M\&E provides room for learning. Lessons are learnt during the process of $M \& E$ and these assist to avoid mistakes done in previous periods and, therefore, to correct the wrongs of the past. As many young revolutionary activists like the mantra, Ruling African National Congress (ANC) wasted 25 years of democracy as since then the development projects they bring to people are either incomplete, they collapse or some die even before they start.

These lessons can be used in the running of future projects. While doing M\&E process, different stakeholders exchange views and improve in the way they communicate to each other and understand weaknesses and strength of each contributing members. 
Role of result-based management monitoring and evaluation in anchoring implementation of development interventions

The process of M\&E follows the project cycle and checks on implementation of the project from initiation to completion. As Bakewell et al. (2003) put it, the M\&E process has levels. These levels are outlined in result-based management (RBM) as the inputs, activities, outputs, outcomes and impact levels.

These authors continue to indicate that outputs include the tangible products that are delivered on the completion of the project activity. It asks a question: what was done? Taking Outcome 1, it will ask what was done to improve the performance of under-performing schools in Limpopo regarding the quality of basic of education.

The outcomes level represents the observable change towards realising objectives of the project and provides room for checking what has happened at a certain stage of the project.

When, for example, going to write next final examinations for grade 12 examinations, the department needs to be able to indicate steps taken and change towards moving a 'serial' poorly performing school in the positive direction. In case of the improvement strategy, there should be an indication of how that was implemented, what were the findings and where does it need to be spruced up. The example in this case will be through the use of extra lessons and tests measuring improvement on subject content understanding of learners and educators.

On the contrary, the impact level concerns long-term changes coming with the project. It is about the long-term improvement in the lives of the stakeholders. On longterm basis, an intervention may result in the realisation of a number of outcomes of the LDP 2015/2019. In giving an example of the realisation of Outcome 1, quality basic education will result in educated people who, in turn, are more likely to get employment and live better lives (Outcome 5: Skilled and capable workforce), who, then, will contribute to building comprehensive rural development (Outcome 7).

According to the Policy Framework for Government-wide Monitoring and Evaluation Systems (GWMES) (2007), if there is no $\mathrm{M} \& \mathrm{E}$, it is more likely that the project may install or take an opposite direction from the conceptual objective.

The following statement used in the Government-wide Monitoring and Evaluation Framework (GWMEF) summarises what may happen should there be no $M \& E$ in all stages of the project:

There was an important job to be done and everybody was sure somebody would do it. Anybody could have done it, but nobody did it. Somebody got angry about that, because it was everybody's job. Everybody thought anybody could do it, but nobody realised that everybody wouldn't do it. It ended up that everybody blamed somebody when nobody did what anybody could have done. GWMEF (2007:44)
This indicates that each process of the project needs to be monitored and be evaluated all the time during implementation. The GWMES (2007) also indicates that the M\&E process involves data collection, processing and analyses and the compilation of a report. This is what Limpopo should do about monitoring the road to the achievement of development interventions. Questions such as 'what needs to be done?', 'by whom?', 'when?' and 'why are we doing it?' should be included.

The office of the Premier has the Provincial M\&E branch that oversees implementation of service delivery interventions across the province. All other departments then have their $\mathrm{M} \& \mathrm{E}$ systems, including establishing directorates for the $\mathrm{M} \& \mathrm{E}$ processes. However, it still has to be proved how effective these directorates are. Some interviewed individuals in the M\&E directorates of the different departments are, however, showing a lack of proper skills in M\&E, as many argue they were 'dumped' to $M \& E$ because there was no more space or importance for them in directorates they were hired to. While some are sourcing M\&E skills, others have lost the hope.

According to the Department of Education Policy on M\&E (2011), it has been noted that there is a need to strengthen and stimulate the performance of government so that its programmes could yield the desired outcomes.

However, there is a challenge that in Limpopo, M\&E processes are not linked to the implementation of development interventions. This is because the function of M\&E seems to be not institutionalised but done haphazardly. The function of M\&E needs to be aligned with the planning.

\section{Finding}

This section focuses on the findings based on the assessment of alignment between implementation of development intervention and the process of M\&E. Monitoring and evaluation is meant for people committed to social development and eager to speed up the process of service delivery (Bakewell et al. 2003). This is also supported by Adejuwon (2014), who argues that many governments in Africa have seen a decline in levels of service delivery because of poor M\&E processes. This then renders the planned development interventions as outlined in the LDP 2015/2019 useless rhetorics as they lack the element of making an impact on the living conditions of the people of Limpopo Province because of poor implementation anchored to a lack of M\&E systems.

The M\&E, as indicated by Wotela (2017b), is a decisionmaking tool. It is unfortunate that in government such as that of the Limpopo Province, the function of M\&E is not linked to planning. Planning, therefore, is done based on nonmethodological findings; hence, the government is failing to provide significant better living conditions year after year. Departments in the province also lack insight into the importance of M\&E; hence they do not literally link this task to their planning. The majority regard M\&E an easy-to-do task; hence, it becomes the dumping zone for those who fell out of political and top administrative favours. 
As the function of M\&E provides accountability, it is imperative that each institution develops effective M\&E tools. Government may not experience projects collapse if planning of M\&E is effectively done, and this can be an anchor for development in the province. These, however, should go with consequence management.

It can be argued that the government of South Africa, including Limpopo, is known to have positive policies for development. However, there is a need to improve the implementation of policies. This can surely be achieved through an effective M\&E function, which will demand accountability. On the contrary, the M\&E process cannot easily be implemented when the APPs of the departments have service delivery indicators that are not related to the outcomes of the LDP 2015/2019 as it has been found.

The LDP 2015/2019 remains in place only for a few months, as it is meant to bring development interventions as planned before the end of 2019. There are 14 outcomes to be achieved. However, there is no effective M\&E process in all the 11 departments of the province. For those that are beginning the business units dealing with $\mathrm{M} \& \mathrm{E}$, there is a lack of capacity and mainly resources and proper skills. The lack of capacity is also influenced by the fact that most of the employees in M\&E are not trained in the field, as they were not hired for such posts but transferred to the task. The Premier's office is also a culprit in this trend. There was a trend of deploying employees no longer needed in positions they were hired for, and probably skilled for, to M\&E and they needed time to adjust before being able to perform well. However, the Provincial Government, in partnership with the University of Witwatersrand (WITS), have started training programme for senior management employees in different fields, including M\&E, recently. This valuable course unfortunately is done at a level that has time limits for providing practical and full M\&E skills.

\section{Conclusion}

As indicated earlier, the main objective of this study is to assess alignment between the implementation of development interventions as outlined in the LDP 2015/2019 and the M\&E processes in Limpopo Province, as well as the impact thereof. The assessment indicates that in many ways, there is a lack of such alignment. In this article, an attempt has been made to provide recommendations which the provincial government can follow to align M\&E and the development interventions.

According to the World Bank Report on M\&E (213), to maximise the impact of $\mathrm{M} \& \mathrm{E}$ on the implementation of development interventions, the M\&E function must be linked to impact evaluation. Impact evaluation is a method used at the result stage of a project to analyse different outcomes. The report continues to indicate that $M \& E$ can be used to increase transparency and therefore raise awareness and promote debates on the running of development interventions. The results of M\&E function, therefore, can be used as a part of budget decision-making. However, the assessment indicates that lack of alignment results in the lack of effective implementation of intervention and also in the waste of resources.

According to the Handbook on monitoring and evaluation for results (2002), the M\&E activities are responsible for the intensified focus on outcomes by shifting towards better measurement of performance that will lead to more systematic reporting. Systematic reporting fosters an organisational culture of learning, transparency and accountability. This study indicates that the reason why the departments repeat intervention implementation mistakes is attributed to the lack of effective M\&E process. The M\&E will also guard against other negative factors for the achievement of set goals, for example, political interference and corruption.

On the contrary, Kusek and Rist (2004) introduced 10 steps to a result-based $M \& E$, which are relevant to the implementation of development interventions in Limpopo Province and any other government. The first step in the M\&E function is to conduct readiness assessment to ensure that all involved in the process are ready. There is again the need to check whether conditions of the project will allow for M\&E processes to avoid a waste of resources. Those involved in M\&E activity should also agree on intended outcomes of the M\&E. Stakeholders need to understand what is expected during the process of M\&E. Performance indicators to be monitored need to be set out clearly and get to be understood by all.

As Kusek and Rist (2004) opine, the other step is to establish a process of gathering data for the indicators. To ensure results contribute to improved development intervention, the planning for improvement should be developed through selecting a result target. The evaluation results are then used to support RBM system. Through finding reporting step, the gains, benefits and failure in the process of the project, it is then revealed as part of feedback. The findings are then used for decision-making to improve service delivery in Limpopo Province. It is unfortunate that the findings indicated that M\&E components in departments are not effective and therefore there cannot be implementation of Kusek and Rist's (2004) 10 steps.

In Limpopo, and with the desire to link M\&E processes to the implementation of development interventions as outlined in LDP 2015/2019, it is recommended that there should be an effective M\&E process that could provide a tracking plan for the realisation of all 14 outcomes. This plan then will be used to track progress daily, weekly, monthly, quarterly and even annually depending on set indicators. With clear evaluation terms, it is more likely that at the end of the MTSF there will be tangible results with and remarkable improvement of living conditions.

\section{Acknowledgements}

The author acknowledges some of the top managers in Limpopo Provincial Government who assisted in ascertaining some of the statements or facts used in this article. The author 
also thanks those who participated as beneficiaries of government interventions who also indicated a recurring lack of impact on the interventions in general living conditions.

\section{Competing interests}

The author declares that he has no financial or personal relationships that may have inappropriately influenced him in writing this article. The intention is to share the findings with the aim of assisting in improving the general service delivery in Government. The views and opinions expressed in this article are those of the author and do not necessarily reflect the official policy or position of any affiliated agency of the author.

\section{References}

Adejuwon, D., 2014, 'Enhancing public accountability and performance in Nigeria: Periscoping the impediments and exploring imperitive measures', Africa's Public Service Delivery \& Performance Review 2(1), 82. https://doi.org/10.4102/apsdpr.v2i2.54

Bakewell, O. Adams, J. \& Pratt, B., 2003, Sharpening the development processes: A practical guide to monitoring and evaluation, Intract, praxis Serial 1, Oxford, Great Britain.
Baradei, L.E., Abdeihamid, D. \& Wally, N., 2014, 'Institutionalising and streamlining development monitoring and evaluation in post-revolutionary Egypt: A readiness primer', African Evaluation Journal 2(1), Art.\#57, 1-6.

Government-wide Monitoring and Evaluation Framework (GWMEF), 2007 'Monitoring and Evaluation Concepts' Department of Planning Monitoring and Evaluation, Pretoria, South Africa.

Government of New York, 2002, Handbook on monitoring and evaluation for results (2002), United Nations, New York.

Kusek, J.Z. \& Rist, R.C., 2004, Ten steps to a result-based monitoring and evaluation, World Bank, Washington, DC.

Limpopo Department of Education, 2011, Policy on monitoring and evaluation, Limpopo Department of Education, Polokwane, Limpopo, South Africa.

Mabanga, T., 2016, Infrastructure essential for Limpopo's continued growth, Mail \& Guardian, Johannesburg.

Masiapato, N. \& Wotela, K., 2017, 'Conceptual framework for subnational citizenbased participatory democracy and empowerment: Case of Vhembe District Municipality', African Journal of Public Affairs 9(5), 103-122.

Rasila, B. \& Mudau, M.J., 2013a, 'Citizen participation in local government: The importance of effective communication in rural development', Internationa Journal of Community Development 1(1), 12-18. https://doi.org/10.11634/ 233028791301321

STATSSA, 2016, Limpopo community survey, Statistics South Africa, Pretoria.

Wotela, K., 2017a, 'Using systems thinking to conceptually link the monitoring and evaluation function within development interventions and public policy', The Journal for Transdisciplinary Research in South Africa 13(1), a398. https://doi. org/10.4102/td.v13i1.398

Wotela, K., 2017b, 'A proposed monitoring and evaluation curriculum based on model that institutionalises monitoring and evaluation', African Evaluation Journal 5(1), 8. https://doi.org/10.4102/aej.v5i1.186 